\title{
Epidemiological characteristics of ovarian cancer in Korea
}

\author{
Boyoung Park ${ }^{1,4, *}$, Sohee Park ${ }^{2, *}$, Tae-Joong Kim ${ }^{3}$, Seung Hyun Ma ${ }^{1,4}$, Byoung-Gie Kim³ ${ }^{3}$, Yong-Man Kim ${ }^{5}$, \\ Jae Weon Kim ${ }^{6}$, Sokbom Kang ${ }^{7}$, Jaehoon Kim ${ }^{8}$, Tae Jin Kim ${ }^{9}$, Keun-Young Yoo ${ }^{1}$, Sue K. Park ${ }^{1,4,10}$
}

\begin{abstract}
${ }^{1}$ Department of Preventive Medicine, Seoul National University College of Medicine, Seoul, ${ }^{2}$ Division of Cancer Registration and Surveillance, National Cancer Center, Goyang, ${ }^{3}$ Department of Obstetrics and Gynecology, Samsung Medical Center, Sungkyunkwan University School of Medicine, Seoul, ${ }^{4}$ Cancer Research Institute, Seoul National University, Seoul, ${ }^{5}$ Department of Obstetrics and Gynecology, Asan Medical Center, University of Ulsan College of Medicine, Seoul,

${ }^{6}$ Department of Obstetrics and Gynecology, Seoul National University Hospital, Seoul National University College of Medicine, Seoul, ${ }^{7}$ Department of Gynecologic Oncology, National Cancer Center, Goyang, ${ }^{8}$ Division of Gynecologic Oncology, Department of Obstetrics and Gynecology, Gangnam Severance Hospital, Yonsei University College of Medicine, Seoul, ${ }^{9}$ Department of Obstetrics and Gynecology, Cheil General Hospital and Women's Healthcare Center,

Kwandong University College of Medicine, Seoul, ${ }^{10}$ Department of Biomedical Science, Seoul National University College of Medicine, Seoul, Korea
\end{abstract}

\begin{abstract}
Objective: This study was conducted to examine recent trends in ovarian cancer incidence and mortality and secular trends in demographic factors in Korea.

Methods: With the data from Korea Central Cancer Registry, International Agency for Research on Cancer, Korean Death Registry, and World Health Organization's Statistical Information System, we calculated age-standardized incidence and mortality rates for ovarian cancer. Also we estimated future incidence of ovarian and cervical cancer using linear regression model. To assess the demographic trend, data from national surveys in Korea or results from published papers were searched.

Results: Ovarian cancer incidence rate was similar to that in women worldwide but lower than those in Western countries, and the trend has been increased steadily. Ovarian cancer-related mortality rates have been increasing in Korea, even though those in western and some Asian countries, such as China, have been decreasing. Age-specific incidence rate and mortality rate showed steep increases with advancing age. The incidence rate of ovarian cancer was estimated to surpass that of uterine cervix cancer in 2015. Korea showed rapid changes in nutritional, reproductive, and anthropometric factors.

Conclusion: These recent trends in ovarian cancer incidence and mortality may be partly attributed to gradual westernizing of life styles and to changes in socio-demographic behavior factors. In particular, the increasing trend in ovarian cancer mortality in Korea may be attributed to a real rise in mortality as well as, in part, a decline in misclassification bias related to an increase in the proportion of deaths confirmed by physician diagnosis.
\end{abstract}

Key Words: Ovarian neoplasms, Epidemiology, Incidence, Mortality

\section{INTRODUCTION}

Ovarian cancer is the second most common gynecological cancer in western women and the most common in the UK. ${ }^{1-3}$ Also, it is the second commonest gynecological cancer, next to uterine cervix cancer, in Korea. ${ }^{4}$ From 1999 to 2007, ovarian cancer (International Classification of Diseases Code 10 [ICD10]: C56) ranked ninth or tenth among women, and the incidence rate for ovarian cancer has been relatively stable

Received October 20, 2010, Revised November 19, 2010,

Accepted November 27, 2010

\section{Correspondence to Sue K. Park}

Department of Preventive Medicine, Seoul National University College of Medicine, 28 Yeongeon-dong, Jongno-gu, Seoul 110-799, Korea Tel: 82-2-740-8338, Fax: 82-2-747-4830

E-mail: suepark@snu.ac.kr

*Equally contributed as the 1 st author. over time, although a slight increase in the incidence rate has been reported. ${ }^{4}$ In contrast, mortality rates for ovarian cancer have been increasing in Korea, even though those in western countries and some Asian countries such as China have been decreasing. ${ }^{1,2,5}$ In this report, we examined the recent trends in ovarian cancer incidence and secular trends in demographic factors of the population in Korea in order to uncover additional factors in ovarian cancer etiology.

\section{MATERIALS AND METHODS}

\section{Cancer incidence}

The Korea National Cancer Center produced the incidence data for cancers based on data collected by the Korea Central Cancer Registry, eight regional cancer registries, national death certification, and nationwide health insurance data. The baseline population for cancer incidence estimation covers most of the entire population of Korea. ${ }^{6}$ For the time-trend analysis and 
international comparison, we used direct age-standardized incidence rates for ovarian cancer (ICD10: C56) using the Segi world standard population. ${ }^{7}$ We used nationwide ovarian cancer incidences for the period 1999-2007. ${ }^{4}$ For comparison of rates with other countries, ovarian cancer rates from the USA, UK, and Japan, were obtained from the International Agency for Research on Cancer (IARC) publication, Cancer Incidence in Five Continents Volume VIII. ${ }^{8}$ The age group $75+$ was an aggregate of age groups 75-79, 80-84, 85-89, 90-94, 95-99, and $100+$.

\section{Mortality}

Based on national death certification data, annual age-specific death rates for ovarian cancer in Korea were acquired from the Korea Statistical Information System (KOSIS) of the National Statistical Office in Korea ${ }^{9}$ for the years 1983-2008. Ovarian cancer rates for the USA, UK, and Japan were obtained from Surveillance, Epidemiology and End Results (SEER) statistics, ${ }^{10}$ and from the Mortality Database of the World Health Organization (WHO)'s Statistical Information System. ${ }^{11}$ All mortality rates were age-adjusted to the Segi world standard population ${ }^{7}$ using the direct method. Our age group 80+ was an aggregate of the age groups 80-84, 85-89, 90-94, 95-99, and 100+.

\section{Future incidence estimation of ovarian cancer and uterine cervix cancer}

Using the incidence rates of ovarian cancer and uterine cervix cancer from 1999 to 2007, we established a linear regression model to estimate the future incidence rate. The regression model was as follows: $Y_{i}=\alpha+\beta t_{k}$, where $t_{k}=$ calendar year and $\mathrm{Y}_{\mathrm{i}}=$ age-standardized incidence rate. We obtained the best-fit $\alpha$ and $\beta$ values using the regression model, and the estimated incidence rates after 2008 were calculated by extrapolation.

\section{Demographic factors}

We accessed the Demographic factors in the three aspects nutritional factors, reproductive factors, and anthropometric factors. To study the changes of nutritional factors, the national data on food consumption from the reports of Korea National Health and Nutrition Examination Survey (KNHANES) by the Ministry of Health and Welfare, ${ }^{12}$ which was based on the amount of nutrients per capita in the food available for consumption in Korea were obtained. Data from national surveys or results from published papers were obtained for reproductive and anthropometric factors. If data from national surveys existed, they were primarily considered but if not, results from papers were considered as alternatives. The sources that we used are described in the Table 1 and Fig. 1.

Table 1. Changes in reproductive, anthropometric and daily dietary intake patterns in Korea

\begin{tabular}{|c|c|c|c|}
\hline Variables [reference] & Results & Results & Change per year \\
\hline \multicolumn{4}{|l|}{ Reproductive factors } \\
\hline \multirow[t]{2}{*}{ Age at menarche (mean) $[13,14]$} & $16.9^{1}$ & $13.8^{2}$ & -0.05 \\
\hline & & $12.0^{3}$ & -0.07 \\
\hline Proportion of women whose menopausal age is over 55 years old (\%) [15] & $6.5^{4}$ & $9.1^{5}$ & +0.33 \\
\hline Oral contraceptive intake rate $(\%)[16]$ & $7.8^{6}$ & $1.1^{7}$ & -0.22 \\
\hline Age at marriage (mean) $[17,18]$ & $23.3^{8}$ & $28.7^{9}$ & +0.19 \\
\hline Crude birth rate (per 100,000$)[17,18]$ & $31.2^{8}$ & $9.0^{9}$ & -0.77 \\
\hline Total fertility rate (per a woman) $[17,18]$ & $4.53^{8}$ & $1.15^{9}$ & -0.12 \\
\hline Proportion of the over three children (\%) [17] & $38.4^{10}$ & $9.6^{11}$ & -0.96 \\
\hline Age at first childbirth (mean) [17] & $24.7^{12}$ & $30.2^{13}$ & +0.22 \\
\hline Breast feeding rate $(\%)[19]$ & $90.0^{8}$ & $24.2^{14}$ & -2.53 \\
\hline Infertility rate $(\%)[20]$ & $13.5^{15}$ & $26.2^{9}$ & +1.41 \\
\hline \multicolumn{4}{|l|}{ Anthropometric factors [21] } \\
\hline Mean BMI of female aged $40-49\left(\mathrm{~kg} / \mathrm{m}^{2}\right)$ & $22.9^{16}$ & $23.6^{5}$ & +0.03 \\
\hline Mean weight of female aged $40-49(\mathrm{~kg})$ & $53.7^{16}$ & $57.4^{5}$ & +0.17 \\
\hline Mean height of female aged $40-49(\mathrm{~cm})$ & $153.1^{16}$ & $156.1^{5}$ & +0.12 \\
\hline \multicolumn{4}{|l|}{ Daily dietary intake factors (\%) } \\
\hline Proportion of calories from fat & $8.6^{10}$ & $18.4^{9}$ & +0.3 \\
\hline Proportion of calories from protein & $12.8^{10}$ & $14.6^{9}$ & +0.05 \\
\hline Proportion of fat intake from meat and meat products & $6.0^{10}$ & $44.2^{9}$ & +1.16 \\
\hline Proportion of protein intake from meat and meat products & $2.3^{10}$ & $45.6^{9}$ & +1.31 \\
\hline \multicolumn{4}{|l|}{ Cancer incidence (per 100,000) [22] } \\
\hline Ovarian cancer incidence rate among women & $5.5^{17}$ & $6.2^{18}$ & +1.7 \\
\hline Breast cancer incidence rate among women & $24.5^{17}$ & $39.9^{18}$ & +6.6 \\
\hline Colorectal cancer incidence rate among women & $17.1^{17}$ & $24.3^{18}$ & +5.3 \\
\hline
\end{tabular}

${ }^{1}$ Those born in 1920-1924. ${ }^{2}$ Those born in 1980-1985. ${ }^{3}$ Those born in after 1990. ${ }^{4}$ Year of $1996 .{ }^{5}$ Year of $2004 .{ }^{6}$ Year of $1976 .{ }^{7}$ Year of 2006. ${ }^{8}$ Year of 1970. ${ }^{9}$ Year of 2009. ${ }^{10}$ Year of 1975. ${ }^{11}$ Year of 2005. ${ }^{12}$ Those born in 1955. ${ }^{13}$ Those born in after 1980. ${ }^{14}$ Year of $2006 .{ }^{15}$ Year of 2000.

${ }^{16}$ Year of 1979. ${ }^{17}$ Year of $1999 .{ }^{18}$ Year of 2007. 


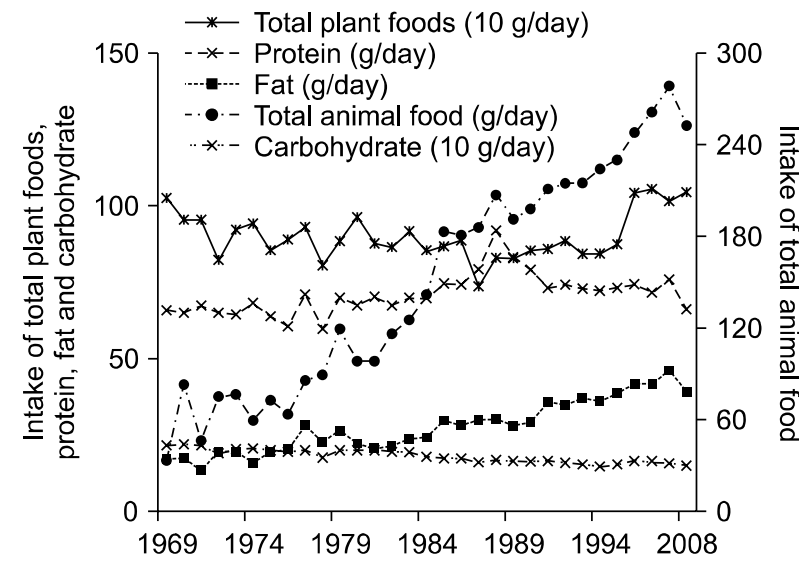

Fig. 1. Changes in dietary patterns in Korea.

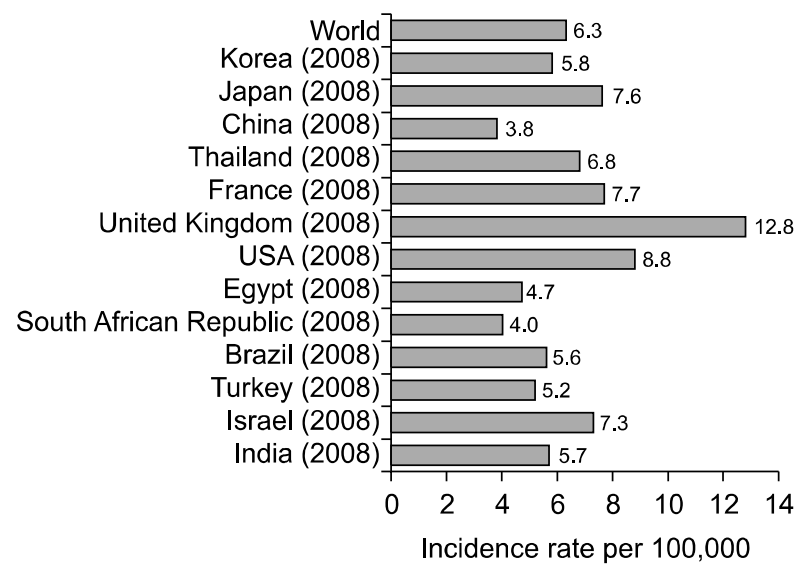

Fig. 2. Global incidence rates (age-standardized, Segi standard population) for ovarian cancers. Source: Globocan, 2008. IARC, 2010.

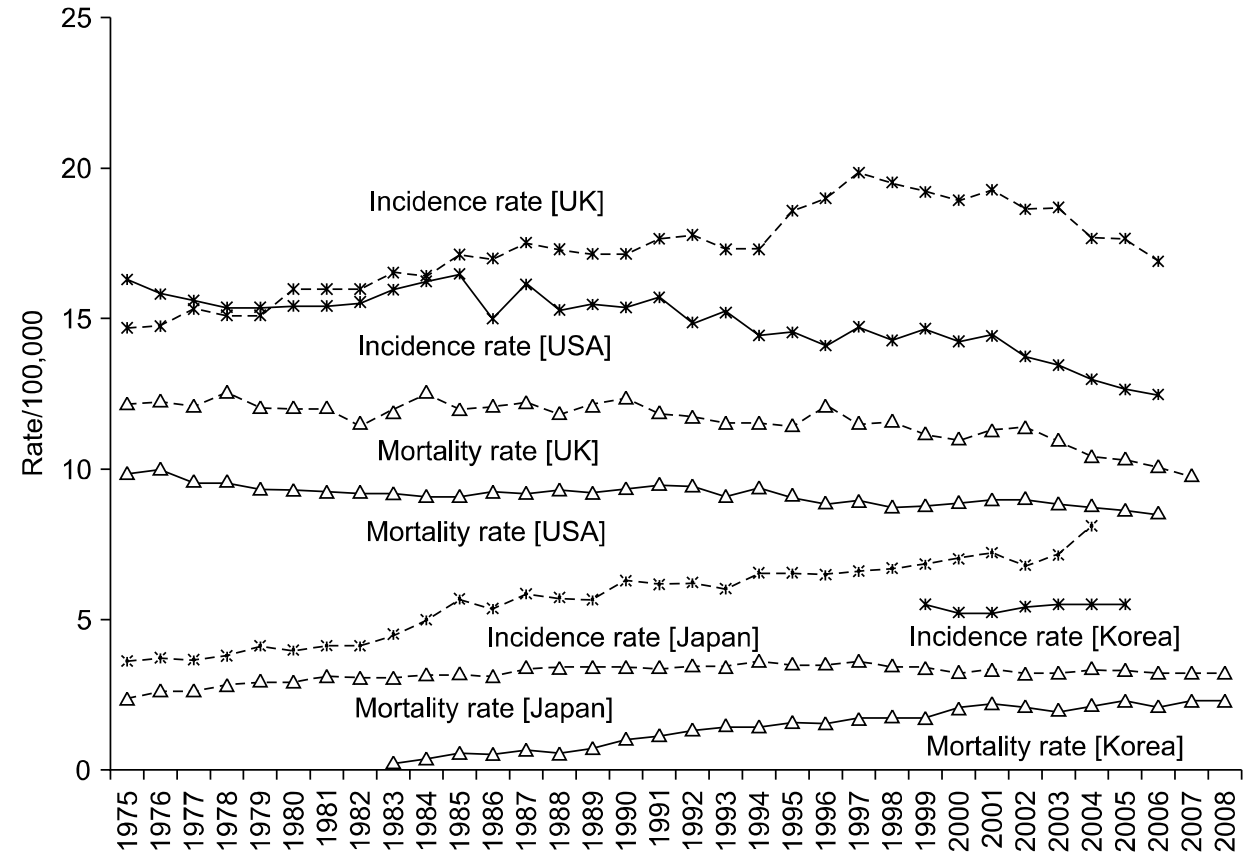

Fig. 3. Age-standardized incidence and mortality rates for ovarian cancer in USA, UK, Japan and Korea. Incidence rate source: Globocan, 2008. IARC, 2010. Mortality rate source: KOSIS, 1983-2005. SEER, 1975-2007.

\section{RESULTS}

Fig. 2 shows the age-adjusted incidence of ovarian cancer in some countries. ${ }^{8}$ Global ovarian cancer incidence rate was 6.3 per 100,000 women-years, and that among Korean women was similar to that of women worldwide (5.8 per 100,000 women-years).

Although the periods for which incidences have been reported were variable, ovarian cancer incidence rates in Asian countries, including Korea, were lower than those in Western countries, including the USA, the UK, and France. The incidence for women in Israel, in which a large proportion of population are Caucasian, was higher than those of other Asian countries. Rates in Korea exceeded only those in China and Egypt where ovarian cancer incidences have been among the lowest in the world.

Fig. 3 shows the trend of age-adjusted incidence and mortality rates related to ovarian cancer in two western countries (the USA and the UK) and two Asian countries (Japan and Korea). In Korea, the nationwide incidence of ovarian cancer was 5.5 per 100,000 women-years in 1999, 5.2 per 100,000 women-years in 2000 and 2001, 5.4 per 100,000 women-years in 2002 , and 5.5 per 100,000 women-years in $2003-2005$. The incidence rate in 2005 rose relative to that of 2000 (5.8\% increase); however, the rate in 2005 was not changeable $(0 \%)$ relative to that of 1999. The age-adjusted incidence rates in Japan has been increasing, while those in the USA have shown a decreasing trend since 1975. Those in the UK had increased until 1997, but since then have decreased. Relative to the incidence rate in 2000 , the rate in 2004 rose $16.0 \%$ in Japan, 

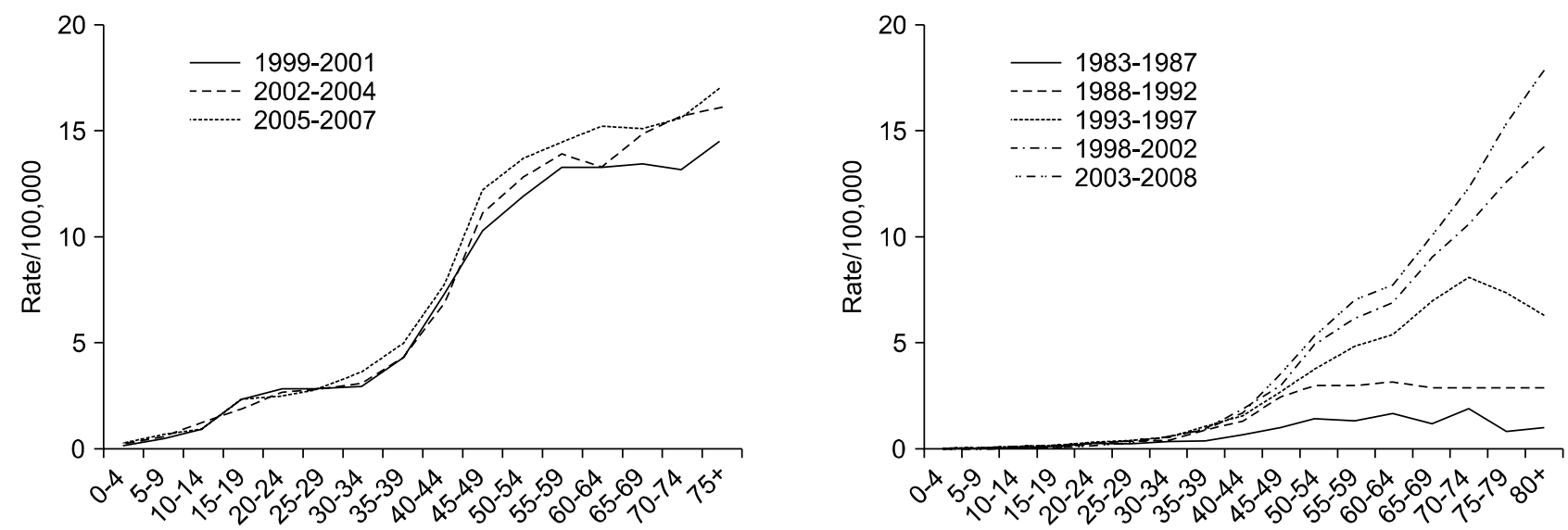

Fig. 4. Age-specific incidence (1999-2007) and mortality rate (1983-2008) in Korea.
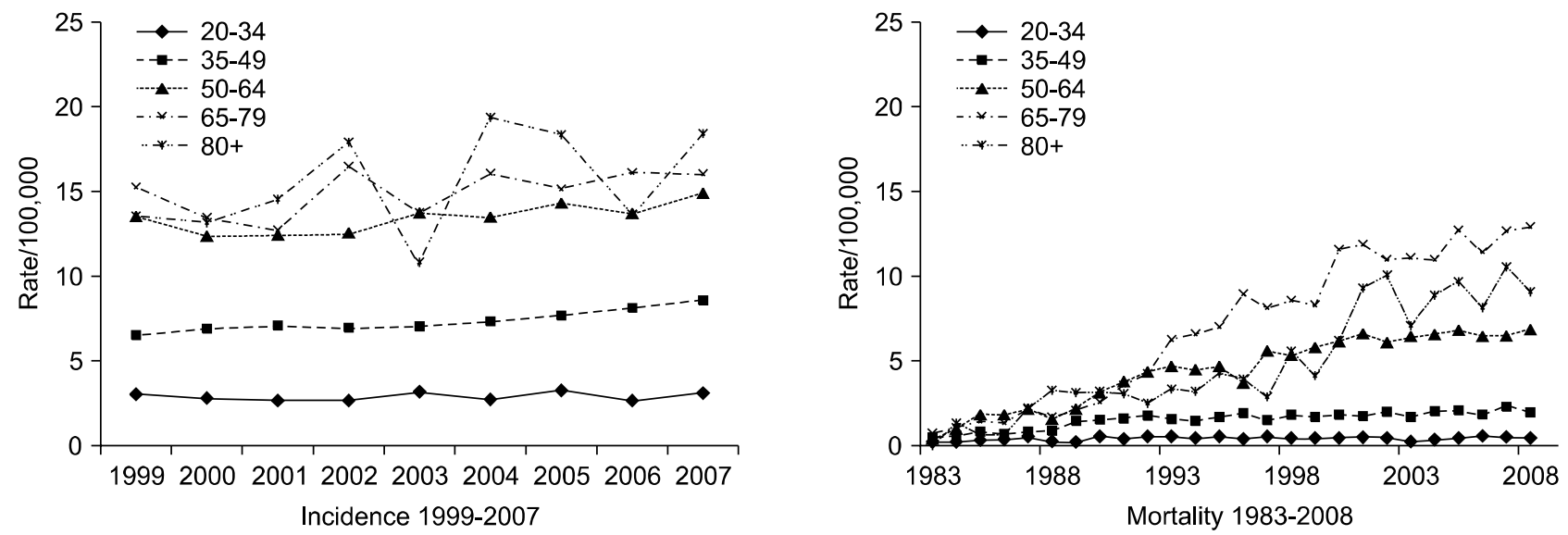

Fig. 5. Yearly changes in age-specific incidence (1999-2007) and mortality rates (1983-2008) in Korea.

while that in 2005 declined $11.2 \%$ in the USA and $6.7 \%$ in the UK.

The mortality rates in the UK have been decreasing since 1975, while those in the USA have fluctuated during that same period. In contrast, those in Japan remained stable after a slight increase in mortality prior to 1987 . Those in Korea have been continually increasing since 1983. Relative to the mortality rate in 1983, the rate in 2006 rose by $831.9 \%$ in Korea, while the rate rose by only $5.3 \%$ in Japan, whereas it declined by $7.2 \%$ and $15.1 \%$ in the USA and the UK, respectively.

Figs. 4 and 5 shows age-specific rates of incidence and mortality for ovarian cancer in Korea. Both the age-specific incidence rate and the age-specific mortality rate showed steep increases with advancing age. Relative to the incidence rate in 1999-2001, the incidence in 2005-2007 had increased. In particular, the incidence gap between 1999-2001 and 2005-2007 was first exhibited in the 25-29 age group and the gap became wider with increases in age categories. The mortality gap between 19831987 and 2003-2008 started in age category 25-29, and the gap also widened with an increase in age category (Fig. 4). From

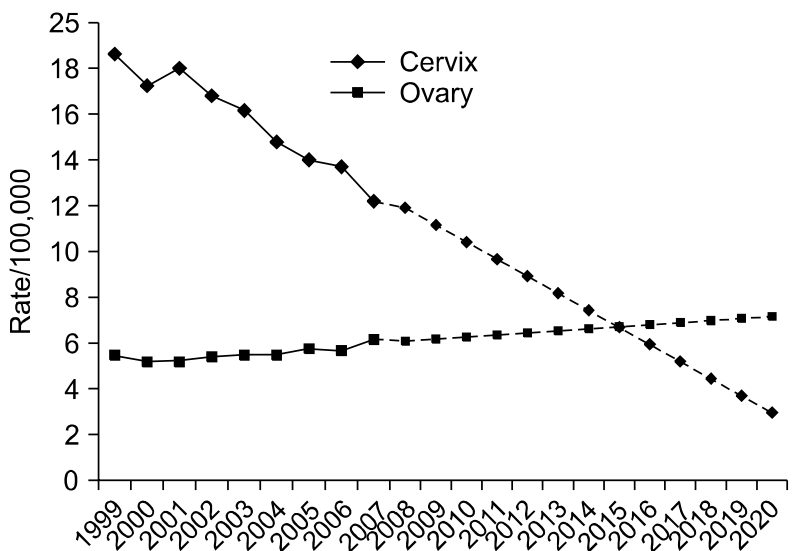

Fig. 6. Future incidence rate estimation in ovarian cancer and uterine cervix cancer in Korea.

1999 to 2007, age-specific incidence rates in the youngest agegroups (under 34 years old) were not changeable, whereas the rates increased in older age-categories. From 1983 to 2008, agespecific mortality rates showed a similar pattern to that of age- 
specific incidence rates. Age-specific incidence and mortality rates in the 65-79 and $80+$ age groups fluctuated year by year; however, increases in both were detected in both age groups (Fig. 5).

Fig. 6 shows estimated age-standardized incidence rates of ovarian and uterine cervix cancers. The incidence rate of ovarian cancer is continually increasing, whereas that of uterine cervix cancer is continuously decreasing. The $\mathrm{R}^{2}$ value of both regression models for ovarian cancer and uterine cervix were 0.98 and 0.97 , respectively. When we assumed that the slope in the rate change regression from 1999 to 2007 is maintained in the future until 2020, the incidence rate of ovarian cancer could surpass that of uterine cervix cancer in 2015, and ovarian cancer may then become the more common gynecological cancer than cervix cancer in Korea.

Fig. 1 and Table 1 presents that the changes in nutritional factors, reproductive factors, and anthropometric factors in Korea. Based on national survey data conducted since 1969, the amount of protein, fat, and animal food intake as well as the percent of calories from fat and protein, and the percent of fat and protein from meat and meat products has been increased. ${ }^{23}$ Age at menarche has been decreasing ${ }^{13,14}$ and the proportion of women whose menopause were delayed increased. ${ }^{15}$ Oral contraceptive agent usage has been decreasing, ${ }^{16}$ otherwise the percentage of infertility among married women has increased recently (from $13.5 \%$ in 2000 to $26.2 \%$ in 2009). In particular, the increasing rate among fertile women aged 30-39 was nearly $78 \%{ }^{23}$ The mean age of women at marriage has risen ${ }^{17,18}$ and the mean age at first childbirth has continued to rise from 24.7 for women born in 1955, to 30.2 years for those born in $1980 .^{24}$ Total fertility rates have declined from $4.53^{24}$ to 1.15 during last 30 years and the proportion of women having more than three children and breast feeding rate has also been decreasing (Table 1). ${ }^{25}$ Also, the obesity rate among Korean women has been increasing. $^{21}$

\section{DISCUSSION}

Age-adjusted ovarian cancer incidence in Korea is much lower than the incidences in Western nations and Japan, but it has been rising steadily over time. In recent years, the rising incidence in Korea is similar to the incidence trends reported in other Asian countries. ${ }^{5,26}$ The mortality rate in Korea is increasing markedly and, from 1983 to 2006, mortality increased 9.5-fold nationwide (from 0.22 per 100,000 personyears in 1983 to 2.09 per 100,000 person-years), although a slightly decrease in mortality rates has been reported in several Western countries such as the USA and the UK, and in some Asian countries such as China. However, the ovarian cancer-related mortality rate in Japan remained relatively stable over time. , $2,20^{-}$

In Korea, the reasons for the increases in ovarian cancer incidence and mortality are unclear, but may be explained in part by the gradual westernization of lifestyles and changes in socio-demographic behavior factors affecting environmental factors in Korea. Western lifestyle factors, such as increased meat and fat consumption, have been linked to elevated ovarian cancer risk in a recent meta-analysis. ${ }^{27}$ In Korea, there has been a shift toward increased westernization of dietary patterns such as increasing the percent of calories from fat and protein, and the percent of fat and protein from meat and meat products (Fig. 1, Table 1). ${ }^{12}$

Some changes in reproductive factors, such as nulliparity, have been shown to have the potential to increase the risk of developing ovarian cancer. The expanding role of women in the work place has led to a shift in the pattern of childbearing to later in reproductive life. In Korea, the mean age of women at marriage and first child birth has risen. ${ }^{17,18,20}$ In addition, fertility rates have declined rapidly. ${ }^{20,24}$ Ovulation-inducing drugs, such as clomifene citrate, were reported to have a relationship with ovarian cancer risk with debate, ${ }^{28,29}$ while infertility among women having normal ovulation has been identified as a risk factor for ovarian cancer. ${ }^{30}$ In Korea, the greater availability of ovarian stimulating drugs due to increased infertility rates among marred women ${ }^{23,31}$ might be expected to influence the increasing trend in ovarian cancer incidence. In Korea, the infertility rate among married women was $13.5-26.5 \%$ (Table 1 ), which is similar or higher than the $10-20 \%$ infertility rate among women in western populations. ${ }^{31}$

One of the leading hypothesis of ovarian cancer is the "incessant ovulation" hypothesis. ${ }^{32}$ According to this hypothesis, increasing lifetime ovulatory cycles by starting menarche earlier, ${ }^{13,14}$ stopping menstruation later ${ }^{15}$ and decreasing oral contraceptives $^{16,33}$ usage in Korea (Table 1) may be one of the important contributing factors to ovarian cancer. Considering that lactation suppresses ovulation and plays a favorable role in ovarian cancer, ${ }^{34}$ decreasing breast feeding rate ${ }^{19}$ might affect increasing ovarian cancer incidence in Korea (Table 1). Also, increasing obesity rate among Korean women ${ }^{21}$ might explain the rapid increase of ovarian cancer among elderly women (Fig. 4, Table 1).

Therefore, changes in socio-demographic, menstrual and reproductive factors, life-style related factors contribute to changes in the incidence of future ovarian cancer in Korea.

The observed regional variation in ovarian cancer incidence, along with dietary patterns further supports our hypothesis that westernization is partly affecting changes in reproductive factors over time. Although ethnic differences or genetic variation such as BRCA mutation are thought to be the main reason for regional variation in ovarian cancer incidence, westernized life styles might affect the regional differences of ovarian cancer to a considerable extent. Age-standardized ovarian cancer incidence and mortality rates have been highest in North America as well as in Northern and Middle Europe, while they have been intermediate in Oceania and South America, and lowest in Asia (including Korea) and Africa. ${ }^{3}$ These differences among world regions may be consistent with westernizing of diet and lifestyle conditions. Also other 
reproductive factors, including longer periods of breast feeding, as well as the use of oral contraceptives and tubal ligation $^{35,36}$ may be different between regions. For example, in Korea, the percentage of oral contraceptive use for the purpose of contraception is very low $(1.8 \%)$ relative to that of western women (15\% in the USA, $25 \%$ in the UK, and $40 \%$ in the Netherlands). This international difference in oral contraceptive use may reflect international differences in ovarian cancer incidence rates.

In particular, the increasing trend in ovarian cancer related mortality in Korea may be attributed to the rise in ovarian cancer incidence rates. Though the mortality rates in westernized countries show a decreasing trend, and even in Japan where the incidence rate was slightly increasing or stable, ovarian cancer mortality rates in Korea have increased steadily. This contradiction in trends may be attributed to declines in misclassification bias. The proportion of death confirmations by physicians' diagnoses may be related to the accuracy of determination of the cause of death; thus, leading to a decreasing misclassification bias. Until 1990, the proportion of deaths confirmed by a physician's diagnosis was much lower than in subsequent years, ${ }^{22}$ potentially leading to an increase in reported ovarian cancer mortality. In another aspect, since the nationwide ovarian cancer incidence has been published since 1999, the mortality of ovarian cancer data may be underestimated because of the lack of incidence information.

In summary, population-based incidence and mortality data in Korea suggest that ovarian cancer incidence and mortality have been low, but are increasing steadily over time. This upward trend may be explained in part by increased westernization of life style factors and changes in reproductive factors due to socio-demographical secular trend. Nevertheless, a major part of the disparity in ovarian cancer incidences between women in Korea and those in western countries such as the USA, remains unexplained. Moreover, although many studies regarding risk factors for ovarian cancer have been reported, there are few studies for behavior-related modifiable risk factors and genetic risk factors. In particular, epidemiological studies into risk factors among Korean women are rare. Based on a continuation of current trends, after 2015, ovarian cancer is estimated to be a more common gynecological cancer than cervical cancer in Korea. However, considering the rapid westernization in Korea and lag time, the increasing pattern would become more rapid than our estimation. Therefore, future quantitative studies with large sample sizes with individual-level exposure estimation and molecular assessment are needed to provide insight into the role of putative risk factors. Such studies will help elucidate the independent and combined effects of environmental and genetic factors in ovarian cancer etiology, and may uncover factors related to racial differences in ovarian cancer risk. In 2009, a National Cancer Institute grant initiated the Korean Epithelial Ovarian Cancer (Ko-EVE) Study, which is aimed at establishing Korean risk factors and is designed to produce evidence-based clinical practice guidelines for epithelial ovarian cancer. It is hoped that the Ko-EVE study will provide unique and important data on the etiology and natural history of Korean epithelial ovarian cancer.

\section{CONFLICT OF INTEREST}

No potential conflict of interest relevant to this article was reported.

\section{ACKNOWLEDGEMENTS}

This study was supported by a grant from the National R\&D Program for Cancer Control, Ministry for Health, Welfare and Family affairs, Republic of Korea (0920010).

\section{REFERENCES}

1. Brewster WR. Temporal trends in ovarian cancer: incidence and mortality across Europe. Nat Clin Pract Oncol 2005; 2: 286-7.

2. Olaitan A, Mocroft A, Jacobs I. Patterns in the incidence of age-related ovarian cancer in South East England 1967-1996. BJOG 2000; 107: 1094-6.

3. World Health Organization. Globocan 2008 [Internet]. Lyon: International Agency for Research on Cancer; [cited $2010 \mathrm{Jul}$ 15]. Available from: http://globocan.iarc.fr/.

4. Ministry for Health, Welfare and Family Affairs. Annual report of cancer incidence (2007), cancer prevalence (2007) and survival (1993-2007) in Korea. Seoul: Ministry for Health, Welfare and Family Affairs; 2009.

5. Kim K, Zang R, Choi SC, Ryu SY, Kim JW. Current status of gynecological cancer in China. J Gynecol Oncol 2009; 20: 72-6.

6. Ahn YO. Cancer registration in Korea: the present and furtherance. J Prev Med Public Health 2007; 40: 265-72.

7. Segi M, Kurihara M. Cancer mortality for selected sites in 24 countries. Sandai: Department of Public Health, Tohoku University of Medicine; 1966.

8. Parkin DM, Whelan SL, Ferlay J, Teppo L, Thomas DB. Cancer incidence in five continents, Vol. VIII. IARC scientific publication No. 155. Lyon: International Agency for Research on Cancer; 2002.

9. Korea National Statistical Office. Korean Statistical Information System (KOSIS): Annual report on the cause of death statistics. 1983-2005 [Internet]. Daejeon: Korea National Statistical Office; [cited 2010 Jul 15]. Available from: http://www.kosis.kr.

10. Altekruse SF, Kosary CL, Krapcho M, Neyman N, Aminou R, Waldron W, et al. SEER cancer statistics review, 1975-2007 [Internet]. Bethesda: National Cancer Institute; 2009 [cited 2010 Jul 15]. Available from: http://seer.cancer.gov/csr/1975_2007/.

11. World Health Organization, Global Healrh Observatory (GHO). Mortality and Burden of Diseases Estimates for WHO Member States in 2004, Table 1: Estimated total female deaths, by cause and WHO member state, 2004 [Internet]. Geneva: World Health Organization; 2009 [cited 2010 Jul 15]. Available from: http://apps. who.int/ghodata/resources/gbddeathdalycountryestimates_fem ale_2004.xls.

12. Ministry of Health \& Welfare, Korean Centers for Disease Control and Prevention. Korea National Health \& Nutrition Examination Survey [Internet]. Seoul: Ministry of Health and Welfare; [cited 2010 Sep 14]. Available from: http://knhanes.cdc.go.kr/.

13. Cho GJ, Park HT, Shin JH, Hur JY, Kim YT, Kim SH, et al. Age at menarche in a Korean population: secular trends and influenc- 
ing factors. Eur J Pediatr 2010; 169: 89-94.

14. Park MJ, Lee IS, Shin EK, Joung H, Cho SI. The timing of sexual maturation and secular trends of menarchial age in Korean adolescents. Korean J Pediatr 2006; 49: 610-6.

15. Park SK, Kang D, Kim Y, Yoo KY. Epidemiologic characteristics of the breast cancer in Korea. J Korean Med Assoc 2009; 52: 937-45.

16. Korea Institute for Health and Social Affairs (KIHASA). National survey data of marriage and fertility transition in 2009 [Internet]. Seoul: Ministry of Health and Welfare; 2009 [cited 2010 Jul 15]. Available from: http://www.mw.go.kr.

17. Korean Statistical Information Service. The population statistics [Internet]. Daejeon: Korea National Statistical Office; [cited 2010 Sep 13]. Available from: http://www.kosis.kr/.

18. Korea National Statistical Office. Population projections for Korea: 2005-2050 [Internet]. Daejeon: Korea National Statistical Office; [cited 2010 Jul 15]. Available from: http://kostat.go.kr.

19. Whittemore AS, Harris R, Itnyre J. Characteristics relating to ovarian cancer risk: collaborative analysis of 12 US case-control studies. II. Invasive epithelial ovarian cancers in white women. Collaborative Ovarian Cancer Group. Am J Epidemiol 1992; 136: 1184-203.

20. Kolahdooz F, van der Pols JC, Bain CJ, Marks GC, Hughes MC, Whiteman DC, et al. Meat, fish, and ovarian cancer risk: results from 2 Australian case-control studies, a systematic review, and meta-analysis. Am J Clin Nutr 2010; 91: 1752-63.

21. Ushijima K. Current status of gynecologic cancer in Japan. J Gynecol Oncol 2009; 20: 67-71.

22. National Cancer Information Center [Internet]. Goyang: National Cancer Center; [cited 2010 Jul 15]. Available from: http://www. cancer.go.kr/cms/statics/incidence/index.html $\# 4$.

23. Kim NI, Lee JH. An analytical review of the methods computing age at first marriage. Korea J Popul Stud 1995; 18: 1-22.

24. Korea National Statistical Office. The pilot result of birth statistics in 2009 [Internet]. Daejeon: Korea National Statistical Office; [cited $2010 \mathrm{Jul} 15]$. Available from: http://kostat.go.kr/.

25. Size Korea. Comparison of estimates according to year [Internet].
Gwacheon: Korea Ministry of Commerce, Industry and Energy; [cited 2010 Oct 10]. Available from: http://sizekorea.kats.go.kr/. 26. Hirabayashi Y, Marugame T. Comparison of time trends in ovary cancer mortality (1990-2006) in the world, from the WHO Mortality Database. Jpn J Clin Oncol 2009; 39: 860-1.

27. Nugent D, Salha O, Balen AH, Rutherford AJ. Ovarian neoplasia and subfertility treatments. Br J Obstet Gynaecol 1998; 105: 584-91.

28. Brinton LA, Moghissi KS, Scoccia B, Westhoff CL, Lamb EJ. Ovulation induction and cancer risk. Fertil Steril 2005; 83: 261-74.

29. Parazzini F, Franceschi S, La Vecchia C, Fasoli M. The epidemiology of ovarian cancer. Gynecol Oncol 1991; 43: 9-23.

30. Hwang N. The status of infertility and policy direction in Korea. Health Welf Policy Forum 2003; 82: 88-97.

31. Risch HA. Hormonal etiology of epithelial ovarian cancer, with a hypothesis concerning the role of androgens and progesterone. J Natl Cancer Inst 1998; 90: 1774-86.

32. Moorman PG, Schildkraut JM, Calingaert B, Halabi S, Vine MF, Berchuck A. Ovulation and ovarian cancer: a comparison of two methods for calculating lifetime ovulatory cycles (United States). Cancer Causes Control 2002; 13: 807-11.

33. Zografos GC, Panou M, Panou N. Common risk factors of breast and ovarian cancer: recent view. Int J Gynecol Cancer 2004; 14: 721-40.

34. Kim HR, Hwang NM, Sim JE, Kim EJ. Analysis of the factors related to nutrition and policy issues for healthy future generation [Internet]. Seoul: Korea Institute for Health and Social Affairs (KIHASA); 2008 [cited 2010 Sep 13]. Available from: http://211. 252.146.15/pub/docu/kr/AK/AA/AKAA2008AAQ/AKAA-200 8-AAQ.PDF

35. Collaborative Group on Epidemiological Studies of Ovarian Cancer, Beral V, Doll R, Hermon C, Peto R, Reeves G. Ovarian cancer and oral contraceptives: collaborative reanalysis of data from 45 epidemiological studies including 23,257 women with ovarian cancer and 87,303 controls. Lancet 2008; 371: 303-14.

36. Jo MW, Khang YH, Yun S, Lee JY, Lee MS, Lee SI. Proportion of death certificates issued by physicians and associated factors in Korea, 1990-2002. J Prev Med Public Health 2004; 37: 345-52. 